ALASKAN GLACIER STUDIES. R. S. TARr and L. MARTin. Washington, National Geographic Society, I9I4. $49^{8}$ pages, 72 text-figures, I76 pages of plates. $26 \mathrm{~cm} . *$

\title{
A Recent Appreciation
}

FOR the past three-quarters of a century, numerous more or less descriptive observations have been made on Alaskan glaciers. Up until the Second World War, most of these were conducted by small field parties, mainly from academic institutions and from U.S. and Canadian government survey projects, and usually but as adjuncts to other work. Some of them were carried out by individuals, usually over only a few days and on a vacation-time basis. This was not so much from lack of realization of the need as from the difficult operational problems posed by the relative inaccessibility and ruggedness of the Alaskan mountain districts. Further deterrents were the heavy cost of work in such regions and the lack of scientific personnel skilled in mountain and glacier travel. As a result, the studies were somewhat limited in nature and extent. In spite of this, valuable photographic records, maps and descriptive reports were produced, especially between 1890 and 1913 and from 1946 to the present.

Most of the earlier studies dealt only with the morphology of the glacial districts or emphasized the mapping of terminal variations of glaciers near sea level. Little serious effort was made to study glacier fluctuations in detail in a selected district until the comprehensive field work of Tarr and Martin in 1909, I910, I91 I and 1913. This research was stimulated by the notable effects of the great earthquakes of $\mathrm{I} 899$, especially in the Yakutat Bay sector of south-eastern Alaska where, at one place, the coast was uplifted a total of $47 \frac{1}{2} \mathrm{ft}$. Several years after this, a number of the ice tongues began to advance. The catastrophic nature of some of these advances prompted the National Geographic Society to make available 17,000 dollars for the five-year study by Ralph Tarr and Lawrence Martin, who had previously visited Yakutat Bay in I905 and 1906.

The results of their expeditions were published in I9I4 under the title "Alaskan Glacier Studies". This monumental work deals admirably with the general description and fluctuation patterns of twenty-five major glaciers in the Yakutat Bay area and of about sixty large glaciers in the vicinity of the Lower Copper River and Prince William Sound. The study, however, was limited to the terminal areas, where a number of observations of interest to the glacial geologist were also reported.

Because of renewed interest in the behaviour of Alaskan glaciers at the present time, especially as it concerns their comparison with other glacial areas throughout the world, this comprehensive report warrants a renewed recognition and appreciation. Four basic contributions of the report might be cited: (I) it has formed a systematic basis for comparative studies on the terminal variations of glaciers in several of the most important glacial districts of coastal Alaska; $(2)$ it has established certain lines of observation which are still valid to-day and locates photographic and survey stations which may be re-occupied; (3) it serves as a helpful summary of all work on Alaskan glaciers prior to 1909 ; and (4) it provides a useful review of the status of general glaciological knowledge up through the first decade of this century.

Tarr and Martin's conclusions regarding the effects of the earthquakes are of special interest in view of field studies at present under way in the source névés of some of the glaciers they described. Whether or not one agrees with their theory of "earthquake avalanche supply", it is gratifying that they tempered their conclusions with the statement that a firm explanation of Alaskan glacier variations would demand many years of observation. To this end, they advocated a connected, long-range study of these glaciers. Their volume has not only stimulated such study but has provided a most useful framework of reference. 'Tarr and Martin's work has been to Alaskan glaciology what Wright and Priestley's work, of the same era, has been to the glaciology of the Antarctic.

Maynard M. Millar

* A limited number of copies of this book is still available to scientific and educational bodies only on official application to the National Geographic Society, Washington 6, D.C. 